\title{
Influence of Two Cooling Methods on Dynamic Mechanical Properties of High Temperature Sandstone
}

\author{
Qi Ping $\mathbb{D}^{1,2,3}{ }^{1}$ Qi Diao, ${ }^{2,3}$ Dezhi Qi, ${ }^{2,3}$ Chen Wang, ${ }^{2,3}$ and Chuanliang Zhang ${ }^{2,3}$ \\ ${ }^{1}$ State Key Laboratory of Mining Response and Disaster Prevention and Control in Deep Coal Mine, \\ Anhui University of Science and Technology, Huainan, Anhui 232001, China \\ ${ }^{2}$ Engineering Research Center of Mine Underground Projects, Ministry of Education, Anhui University of Science and Technology, \\ Huainan, Anhui 232001, China \\ ${ }^{3}$ School of Civil Engineering and Architecture, Anhui University of Science and Technology, Huainan, Anhui 232001, China
}

Correspondence should be addressed to Qi Ping; ahpingqi@163.com

Received 23 April 2021; Accepted 6 July 2021; Published 19 July 2021

Academic Editor: Honglue Qu

Copyright (C) 2021 Qi Ping et al. This is an open access article distributed under the Creative Commons Attribution License, which permits unrestricted use, distribution, and reproduction in any medium, provided the original work is properly cited.

To study the influence of different cooling methods on dynamic mechanical properties of high temperature rock, both natural cooling and water cooling were used to cool high temperature $\left(100^{\circ} \mathrm{C} \sim 1000^{\circ} \mathrm{C}\right)$ coal mine sandstone to room temperature $\left(20^{\circ} \mathrm{C}\right)$. Basic physical parameters of sandstone were measured, and impact compression tests were carried out by using the SHPB test device. Comparative analysis shows that the volume expansion rate, mass loss rate, density reduction rate, and P-wave velocity reduction rate of sandstone specimens are positively correlated with the temperature in a quadratic function. The deteriorate rate of physical parameters of water cooling sandstone specimens is slightly larger than that of natural cooling. The variation of dynamic stress-strain curves is basically consistent. Compaction stage of water cooling is slightly larger than that of natural cooling. With the increase in temperature, dynamic compressive strength of sandstone specimens first increases, then decreases, and reaches maximum at $300^{\circ} \mathrm{C}$. Subsequently, dynamic compressive strength decreases in a quadratic function with the temperature, and dynamic compressive strength of water cooling sandstone specimens is significantly lower than that of natural cooling. The dynamic elastic modulus also first increases and then decreases with the temperature and reaches maximum at $300^{\circ} \mathrm{C}$. The dynamic elastic modulus of water cooling sandstone specimens is lower than that of natural cooling, but they are roughly the same at $1000^{\circ} \mathrm{C}$. Dynamic strain increases in a quadratic function with the temperature, and dynamic strain of water cooling sandstone specimens is greater than that of natural cooling. The impact failure of sandstone specimens is intensified with the temperature, and the failure degree of water cooling is greater than that of natural cooling.

\section{Introduction}

Rock often experiences long-term high temperature heating and rapid cooling in geotechnical engineering and other fields. During the warring states period in China, Li Bing used the method of first heating rock then rapid cooling with water to excavate mountains for the Dujiangyan Irrigation Project. Modern tunnels and underground caverns may encounter fire and explosion accidents, and the rock walls of tunnels and caverns may experience fire extinguishing and water cooling after long-term high temperature heating. The permeability of water to rocks is bound to affect the selfbearing capacity of tunnels $[1,2]$. When the wildfires are extinguished by planes dropping water, the properties of rock are changed after high temperature. Therefore, studying the physical and mechanical properties of rock after different high temperature treatments has significance for the safe production and disaster prevention.

Some scholars have conducted experimental studies on static and dynamic mechanics of rock under and after high temperature. Sirdesai et al. [3] conducted high temperature heating of fine-grained red sandstone at $50^{\circ} \mathrm{C} \sim 500^{\circ} \mathrm{C}$ for 5 , $10,15,20$, and 30 days and studied the effects of thermal treatment duration on the physical properties and tensile strength of red sandstone. Yang et al. [4] conducted the Brazilian splitting test and conventional triaxial compression 
test for granite with two grain sizes after high temperature treatment and found that the mechanical properties of coarse grain granite are more sensitive to temperature than fine grain granite. Gao et al. [5] carried out 4 grades temperature treatment for Fangshan marble and conducted dynamic compression tests under dry and saturated conditions. Ping et al. [6, 7] studied the dynamic mechanical energy evolution characteristics of limestone under high temperature and carried out the experimental study on dynamic splitting tensile of high temperature sandstone under different loading rates. Experimental studies on wave characteristics and dynamic mechanical properties of granite after different high temperatures were conducted by the ultrasonic analyzer and SHPB device [8]. Zhang et al. [9] carried out uniaxial compression tests under 5 kinds of loading rates for $200^{\circ} \mathrm{C}$ limestone. The experimental study on dynamic mechanical properties of limestone and sandstone after different high temperatures was carried out by Ping et al. [10, 11]. Liu et al. [12] studied the impact dynamic characteristics of marble after different temperatures treatment. Li et al. [13] conducted high temperature heating treatment of Beishan granite, and then uniaxial and triaxial compression tests were carried out with different impact velocities. The above tests are the experimental study on different kinds of rock after high temperature heating and natural cooling treatment.

Some scholars also have carried out a series of experimental studies on statics, acoustics, and physical properties of high temperature rock after water cooling. Xi and Zhao [14] carried out the uniaxial compression test, tensile test, shear test, and ultrasonic velocity test for high temperature granite within $600^{\circ} \mathrm{C}$ after water cooling. Physical and mechanical properties, such as porosity, pore size distribution, compressive strength, peak strain, and microstructure, were studied for five temperatures yellow sandstone in Hanzhong area of Shanxi Province after two cooling methods (water cooling and natural cooling) [15]. Zhu et al. [16] heated granite to high temperature within $500^{\circ} \mathrm{C}$ and tested density, P-wave and $\mathrm{S}$-wave velocities, uniaxial compressive strength, and elastic modulus after water cooling. Experimental analysis of mechanical and wave properties of limestone and marble after high temperature water cooling was conducted by Huang et al. [17, 18]. Han et al. [19] studied the mechanical behaviour of high temperature sandstone after water cooling. Concrete specimens were treated by natural cooling and water cooling after high temperature heating and then the uniaxial compressive test was carried out [20]. Wang et al. [21] conducted $20^{\circ} \mathrm{C} \sim 800^{\circ} \mathrm{C}$ high temperature heating and rapid water cooling for granite and studied the influence of rapid water cooling on residual mechanical properties of high temperature granite. Shi et al. [22] conducted cyclic heating and water cooling for granite specimens and studied the physical and mechanical properties. The effects of two cooling rates on P-wave velocity, uniaxial compressive strength, tensile strength, and fracture toughness of sandstone were studied by cooling with water and liquid nitrogen after high temperature treatment [23]. The uniaxial compression test, velocity test, acoustic emission test, and electron microscope scanning test were carried out for $100^{\circ} \mathrm{C}$ to $800^{\circ} \mathrm{C}$ sandstone after water cooling, and then the influence of thermal shock caused by rapid cooling on the mechanical properties of sandstone was studied [24]. Rathnaweera et al. [25] studied the influence of natural cooling and water cooling on mechanical behaviour of clayrich Hawkesbury sandstone after heating from $25^{\circ} \mathrm{C}$ to $1000^{\circ} \mathrm{C}$. With the MTS322 test system, fracture toughness was tested for granite subjected to $1,5,10,15$, and 20 cycles of heating and water cooling treatment [26]. Through laboratory tests, the physical and mechanical properties of granite after 1 and 30 cycles of heating and water cooling from $20^{\circ} \mathrm{C}$ to $500^{\circ} \mathrm{C}$ were studied [27]. Zhu et al. [28] carried out the impact test of water cooling high temperature granite by using the split Hopkinson pressure bar device. Zhai et al. [29] carried out high temperature heating on C35 concrete under two heating gradients. After natural cooling and water cooling, SHPB impact compression tests under different loading rates were carried out to study the fracture distribution, fractal characteristics, energy dissipation, and dynamic mechanical properties.

At present, the tests and research studies on rock after high temperature water cooling are mostly concentrated in static condition, and the research on dynamic properties of high temperature rock after water cooling is still less. However, in practical engineering, some tunnels and underground caverns after fire may still suffer the impact of traffic accidents, explosions, and earthquakes. Therefore, it is necessary to study the dynamic mechanical properties of high temperature rock after water cooling.

To compare the effects of two cooling methods on the physical and dynamic mechanical properties of high temperature sandstone, common roadway sandstone in coal mine was selected as research object. Sandstone specimens were heated from room temperature $\left(20^{\circ} \mathrm{C}\right)$ to $100^{\circ} \mathrm{C}, 200^{\circ} \mathrm{C}$, $300^{\circ} \mathrm{C}, 400^{\circ} \mathrm{C}, 500^{\circ} \mathrm{C}, 600^{\circ} \mathrm{C}, 700^{\circ} \mathrm{C}, 800^{\circ} \mathrm{C}, 900^{\circ} \mathrm{C}$, and $1000^{\circ} \mathrm{C}$ and then cooled by water cooling and natural cooling. The basic physical parameters of sandstone were measured, and the variation of mass, volume, density, and P-wave velocity was analyzed. Impact compression tests were carried out for high temperature sandstone specimens after cooling under the same loading conditions by $\phi 50 \mathrm{~mm}$ SHPB test apparatus. The influence of two cooling methods on dynamic parameters such as dynamic compressive stress-strain curve, dynamic compressive strength, dynamic elastic modulus, dynamic strain, and strain rate was analyzed.

\section{Materials and Methods}

2.1. Processed Samples. Sandstone samples were taken from Gubei Coal Mine of Huainan Mining Group. In order to enhance the comparison of test results, tested sandstone specimens were drilled from the same rock block. According to test methods recommended by the International Society of Rock Mechanics (ISRM) [30], sandstone specimens were processed into cylinder with the size of $\phi 50 \mathrm{~mm} \times 25 \mathrm{~mm}$, and the aspect ratio is 0.5 to meet the requirements of stress equilibrium and inertial effect in the SHPB test.

Vertical drilling machine, cutting machine, double-end grinding machine, and other equipment were applied to 
core, cut, and polish sandstone specimens to achieve good uniformity and consistency. The roughness of two end of sandstone specimen is less than $\pm 0.02 \mathrm{~mm}$, the nonparallelism of the two ends is less than $\pm 0.05 \mathrm{~mm}$, and the axis deviation is less than $\pm 0.25^{\circ}$. The mass, volume, and P-wave velocity of all specimens were measured before heating. The density was $2.605 \mathrm{~g} / \mathrm{cm}^{3}$, and the P-wave velocity was $3862 \mathrm{~m} / \mathrm{s}$.

\subsection{Heating and Cooling Treatment of Specimens.} Sandstone specimens were heated by box-type resistance furnace equipped with an electric furnace temperature controller. The highest heating temperature of box-type resistance furnace is $1200^{\circ} \mathrm{C}$. In order to heat the specimen fully and uniformly, the heating rate was set as $10^{\circ} \mathrm{C} / \mathrm{min}$ and then the temperature is kept constant for $4^{\circ} \mathrm{h}$ after reaching the target temperature.

After heating, sandstone specimens were taken out from the furnace. For the water cooling method, sandstone specimens were quickly put into the water tank (Figure 1). A piece of toughened glass was put at the bottom of the tank to avoid high temperature sandstone specimens burn the bottom of the tank. The height of ordinary tap water in the tank is about $40 \mathrm{~mm}$ to ensure sandstone specimens immersed in water. For the nature cooling method, sandstone specimens were taken out from the furnace to prevent the residual temperature in the furnace from continuously heating the sandstone specimens so as to avoid the large deviation between two cooling methods due to different heating time.

After sandstone specimens were heated and cooled, the mass, volume, and longitudinal wave velocity were measured for the second time so as to study the influence of physical parameters of sandstone after two cooling methods.

\subsection{Impact Compression Test. SHPB test apparatus in the} State Key Laboratory of Mining Response and Disaster Prevention and Control in Deep Coal Mine was adopted for the impact compression test (Figure 2).

Input bar, output bar, and absorption bar of SHPB test apparatus are all made of high-strength alloy steel. The diameter of SHPB test apparatus is $50 \mathrm{~mm}$, the elastic modulus is $210 \mathrm{GPa}$, and the longitudinal wave velocity is $5190 \mathrm{~m} / \mathrm{s}$. Spindle-shaped striker was used to generate semisine loading wave, ensure the stress equilibrium during impact process, and prevent the specimen from premature failure. Compressed gas used for impact is nitrogen. The pressure for each impact compression test was set as $0.3 \mathrm{MPa}$. The spindle-shaped striker was placed in the same position in the launch tube each time to make the gas act on the striker equally, ensure the consistency of impact load, and keep the incident energy within the same range.

\section{Results and Analysis}

3.1. Results of Basic Physical Parameters. 11 temperature gradients were set up in this research, which were room temperature $\left(20^{\circ} \mathrm{C}\right), 100^{\circ} \mathrm{C}, 200^{\circ} \mathrm{C}, 300^{\circ} \mathrm{C}, 400^{\circ} \mathrm{C}, 500^{\circ} \mathrm{C}$,

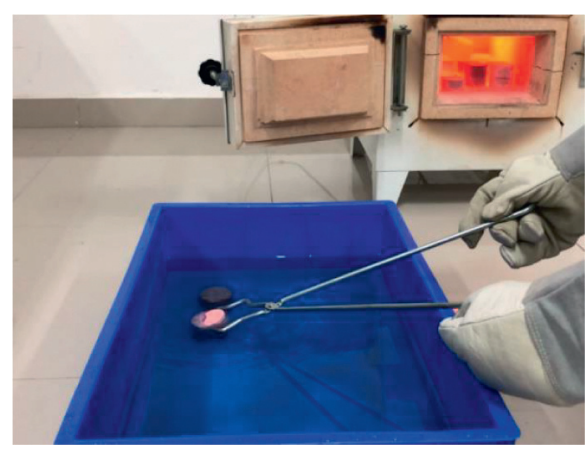

Figure 1: Water cooling treatment for heated sandstone.

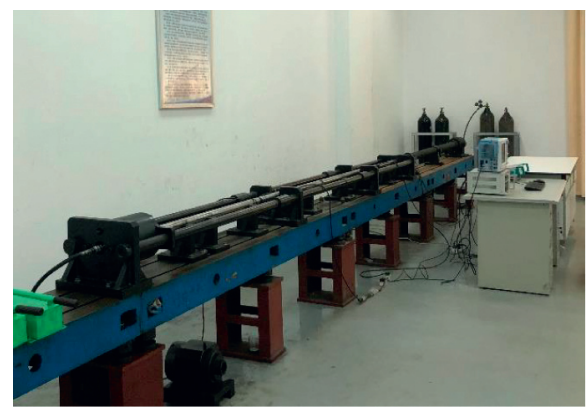

Figure 2: Split Hopkinson pressure bar test apparatus.

$600^{\circ} \mathrm{C}, 700^{\circ} \mathrm{C}, 800^{\circ} \mathrm{C}, 900^{\circ} \mathrm{C}$, and $1000^{\circ} \mathrm{C}$. Tables 1 and 2 list the basic physical parameters of sandstone specimens before heating and after two cooling methods, such as volume, mass, density, and longitudinal wave velocity.

3.2. Variation of Volume, Mass, and Density of Specimens. Figures $3 \sim 5$ are the deteriorate rates of volume, mass, and density of high temperature sandstone specimens after two cooling methods.

As seen from Figure 3, volume expansion rate of water cooling sandstone specimens is greater than that of natural cooling, and the volume expansion rate of high temperature sandstone specimens after two cooling methods first decreases slightly and then increases with the heating temperature, and there is a quadratic function between volume expansion rate and temperature. At $100^{\circ} \mathrm{C} \sim 500^{\circ} \mathrm{C}$, the specimen volume of two cooling methods is less affected by temperature, and there is no obvious expansion. Because the volume expansion of mineral particles within this temperature range only occupies the original micropore and microcrack space inside the specimen, the volume expansion is not obvious. When heated to $600^{\circ} \mathrm{C} \sim 1000^{\circ} \mathrm{C}$, the specimen volume of two cooling methods begins to expand rapidly. This is because the original micropores and microcracks in the specimen exceed the limit of structural thermal stress. With the continuous thermal expansion of sandstone mineral particles, new microcracks generate inside the sandstone specimen, and the appearance volume expands rapidly. When the heating temperature was $1000^{\circ} \mathrm{C}$, the volume expansion rates for natural cooling and water cooling were $4.47 \%$ and $4.69 \%$. The volume expansion rate of 
TABLE 1: Basic physical parameters of sandstone before heating and after water cooling.

\begin{tabular}{|c|c|c|c|c|c|c|c|c|c|c|c|}
\hline \multirow{2}{*}{$T\left({ }^{\circ} \mathrm{C}\right)$} & \multirow{2}{*}{ Samples } & \multicolumn{5}{|c|}{ Before heating } & \multicolumn{5}{|c|}{ After water cooling } \\
\hline & & $D(\mathrm{~mm})$ & $L(\mathrm{~mm})$ & $M(\mathrm{~g})$ & $P\left(\mathrm{~g} \cdot \mathrm{cm}^{-3}\right)$ & $C\left(\mathrm{~m} \cdot \mathrm{s}^{-1}\right)$ & $D(\mathrm{~mm})$ & $L(\mathrm{~mm})$ & $M(\mathrm{~g})$ & $\rho\left(\mathrm{g} \cdot \mathrm{cm}^{-3}\right)$ & $C\left(\mathrm{~m} \cdot \mathrm{s}^{-1}\right)$ \\
\hline \multirow{3}{*}{20} & GB11-01 & 49.96 & 25.18 & 127.40 & 2.582 & 3934 & 49.96 & 25.18 & 127.40 & 2.582 & 3934 \\
\hline & GB11-02 & 49.78 & 25.21 & 127.85 & 2.606 & 3939 & 49.78 & 25.21 & 127.85 & 2.606 & 3939 \\
\hline & GB11-03 & 49.69 & 25.11 & 126.52 & 2.599 & 3923 & 49.69 & 25.11 & 126.52 & 2.599 & 3923 \\
\hline \multirow{3}{*}{100} & GB11-09 & 49.70 & 25.22 & 127.67 & 2.610 & 3708 & 49.60 & 25.14 & 127.41 & 2.624 & 3927 \\
\hline & GB11-13 & 49.74 & 25.37 & 128.77 & 2.613 & 3731 & 49.63 & 25.37 & 128.41 & 2.616 & 3731 \\
\hline & GB11-15 & 49.86 & 25.07 & 126.22 & 2.579 & 3917 & 49.67 & 25.00 & 125.96 & 2.601 & 3676 \\
\hline \multirow{3}{*}{200} & GB11-17 & 49.64 & 25.14 & 127.08 & 2.612 & 3929 & 49.68 & 25.06 & 126.31 & 2.601 & 3481 \\
\hline & GB11-18 & 49.75 & 25.08 & 127.26 & 2.611 & 4179 & 49.69 & 25.06 & 126.47 & 2.603 & 3685 \\
\hline & GB11-19 & 49.78 & 25.13 & 127.77 & 2.612 & 4188 & 49.71 & 25.15 & 127.10 & 2.604 & 3930 \\
\hline \multirow{3}{*}{300} & GB11-25 & 49.85 & 25.25 & 127.74 & 2.592 & 3945 & 49.70 & 25.19 & 129.45 & 2.650 & 3314 \\
\hline & GB11-27 & 49.67 & 25.12 & 126.17 & 2.593 & 3693 & 49.71 & 25.08 & 126.44 & 2.597 & 3689 \\
\hline & GB11-28 & 49.79 & 25.08 & 127.11 & 2.603 & 3918 & 49.71 & 25.07 & 125.59 & 2.580 & 3484 \\
\hline \multirow{3}{*}{400} & GB11-33 & 49.68 & 25.19 & 127.77 & 2.618 & 4198 & 49.64 & 25.17 & 126.99 & 2.607 & 3496 \\
\hline & GB11-35 & 49.74 & 24.99 & 126.10 & 2.597 & 4165 & 49.68 & 24.98 & 125.34 & 2.589 & 3470 \\
\hline & GB11-36 & 49.66 & 25.09 & 127.53 & 2.625 & 3689 & 49.72 & 25.07 & 126.80 & 2.606 & 3481 \\
\hline \multirow{3}{*}{500} & GB11-41 & 49.69 & 24.90 & 126.72 & 2.625 & 3661 & 49.71 & 25.12 & 125.11 & 2.567 & 3305 \\
\hline & GB11-43 & 49.74 & 24.93 & 126.62 & 2.614 & 3462 & 49.75 & 25.00 & 124.39 & 2.560 & 3289 \\
\hline & GB11-44 & 49.73 & 25.22 & 127.41 & 2.601 & 3708 & 49.78 & 25.19 & 125.98 & 2.570 & 3403 \\
\hline \multirow{3}{*}{600} & GB11-51 & 49.77 & 25.17 & 126.84 & 2.591 & 3495 & 49.98 & 25.32 & 120.53 & 2.427 & 2345 \\
\hline & GB11-52 & 49.76 & 25.19 & 126.90 & 2.591 & 4198 & 49.99 & 25.22 & 120.81 & 2.441 & 2335 \\
\hline & GB11-53 & 49.91 & 25.15 & 127.68 & 2.595 & 3929 & 49.93 & 25.22 & 123.14 & 2.494 & 2425 \\
\hline \multirow{3}{*}{700} & GB11-61 & 49.66 & 25.02 & 125.83 & 2.597 & 3474 & 50.18 & 25.26 & 119.27 & 2.388 & 2105 \\
\hline & GB11-62 & 49.65 & 25.14 & 127.47 & 2.619 & 3928 & 50.06 & 25.41 & 120.39 & 2.408 & 1629 \\
\hline & GB11-63 & 49.72 & 25.16 & 127.36 & 2.608 & 3931 & 50.26 & 25.35 & 121.23 & 2.411 & 2264 \\
\hline \multirow{3}{*}{800} & GB11-71 & 49.60 & 25.18 & 126.41 & 2.599 & 3703 & 50.00 & 25.40 & 117.90 & 2.365 & 1716 \\
\hline & GB11-72 & 49.68 & 25.20 & 126.94 & 2.599 & 3500 & 50.10 & 25.46 & 119.20 & 2.376 & 1872 \\
\hline & GB11-73 & 49.79 & 25.23 & 128.10 & 2.608 & 3710 & 50.19 & 25.39 & 118.81 & 2.366 & 1983 \\
\hline \multirow{3}{*}{900} & GB11-81 & 49.72 & 25.18 & 127.47 & 2.608 & 4196 & 50.29 & 25.48 & 119.32 & 2.358 & 1633 \\
\hline & GB11-82 & 49.80 & 25.26 & 128.10 & 2.604 & 3946 & 50.32 & 25.54 & 116.45 & 2.294 & 1520 \\
\hline & GB11-83 & 49.53 & 25.14 & 126.34 & 2.608 & 3697 & 50.16 & 25.39 & 118.32 & 2.359 & 1627 \\
\hline \multirow{3}{*}{1000} & GB11-90 & 49.87 & 25.19 & 127.66 & 2.595 & 4198 & 50.48 & 25.55 & 119.00 & 2.327 & 1452 \\
\hline & GB11-91 & 49.73 & 25.17 & 126.57 & 2.590 & 4194 & 50.52 & 25.62 & 117.60 & 2.291 & 1489 \\
\hline & GB11-93 & 49.70 & 25.05 & 127.65 & 2.626 & 3914 & 50.46 & 25.54 & 116.47 & 2.281 & 1485 \\
\hline
\end{tabular}

water cooling is generally slightly larger than that of natural cooling. The reason is that after the high temperature specimen is naturally cooled in the air, the thermal expansion of mineral particles will gradually shrink due to cooling, so the overall volume of the specimen will be smaller than that of the high temperature state after cooling. When the high temperature specimen is cooled in water, there will be a huge temperature difference between the inside and outside of the high temperature specimen, which will cause additional damage to the specimen. The size and number of micropores and microcracks in the specimen increase resulting in a larger volume expansion rate of water cooling than natural cooling.

As illustrated in Figure 4, mass loss rate of high temperature sandstone specimens after two cooling methods is also positively correlated with temperature in a quadratic function. When the temperature is in the range of $100^{\circ} \mathrm{C} \sim 500^{\circ} \mathrm{C}$, mass loss rate of two cooling methods is small. The mass loss rates of natural cooling and water cooling are $0.21 \% \sim 2.66 \%$ and $0.23 \% \sim 1.38 \%$. When heated to $600^{\circ} \mathrm{C} \sim 700^{\circ} \mathrm{C}$, the mass loss rates of two cooling methods increase obviously. The mass loss rates of natural cooling and water cooling are $4.94 \% \sim 6.24 \%$ and $4.44 \%$ $5.19 \%$. When heated to $800^{\circ} \mathrm{C} \sim 1000^{\circ} \mathrm{C}$, the mass loss rates of natural cooling and water cooling are $6.54 \% \sim 7.38 \%$ and $6.69 \% \sim 7.54 \%$, and the mass loss rate of two cooling methods is basically the same. It is worth noting that the mass loss rate of water cooling is slightly lower than that of natural cooling when the temperature is between $300^{\circ} \mathrm{C}$ and $700^{\circ} \mathrm{C}$. That is because when high temperature sandstone is cooled in water, the water can enter into the internal pores of sandstone, which increases the mass of sandstone. When the action temperature ranges from $800^{\circ} \mathrm{C}$ to $1000^{\circ} \mathrm{C}$, there are many micropores and microcracks in the specimen, and the pore diameter and crack width are large. Even if water is immersed into the sandstone sample, it will gradually evaporate and drain after being removed from the water. Therefore, the mass loss rate of water-cooled specimen is basically same with that of natural cooling.

Figure 5 illustrates that the density reduction rate of sandstone specimens after two cooling methods is positively correlated with temperature in a quadratic function. At $100^{\circ} \mathrm{C} \sim 500^{\circ} \mathrm{C}$, the density reduction rate of two cooling 
TABLE 2: Basic physical parameters of sandstone before heating and after natural cooling.

\begin{tabular}{|c|c|c|c|c|c|c|c|c|c|c|c|}
\hline \multirow{2}{*}{$T\left({ }^{\circ} \mathrm{C}\right)$} & \multirow{2}{*}{ Samples } & \multicolumn{5}{|c|}{ Before heating } & \multicolumn{5}{|c|}{ After natural cooling } \\
\hline & & $D(\mathrm{~mm})$ & $L(\mathrm{~mm})$ & $M(\mathrm{~g})$ & $P\left(\mathrm{~g} \cdot \mathrm{cm}^{-3}\right)$ & $C\left(\mathrm{~m} \cdot \mathrm{s}^{-1}\right)$ & $D(\mathrm{~mm})$ & $L(\mathrm{~mm})$ & $M(\mathrm{~g})$ & $\rho\left(\mathrm{g} \cdot \mathrm{cm}^{-3}\right)$ & $C\left(\mathrm{~m} \cdot \mathrm{s}^{-1}\right)$ \\
\hline \multirow{3}{*}{20} & GB11-05 & 49.90 & 25.06 & 127.51 & 2.602 & 3916 & 49.90 & 25.06 & 127.51 & 2.602 & 3916 \\
\hline & GB11-06 & 49.85 & 25.20 & 127.58 & 2.594 & 3937 & 49.85 & 25.20 & 127.58 & 2.594 & 3937 \\
\hline & GB11-07 & 49.74 & 25.19 & 127.47 & 2.604 & 3936 & 49.74 & 25.19 & 127.47 & 2.604 & 3936 \\
\hline \multirow{3}{*}{100} & GB11-12 & 49.74 & 25.12 & 126.78 & 2.598 & 3489 & 49.53 & 25.21 & 126.50 & 2.605 & 3501 \\
\hline & GB11-14 & 49.80 & 25.17 & 128.04 & 2.612 & 4194 & 49.70 & 25.18 & 127.75 & 2.616 & 3497 \\
\hline & GB11-16 & 49.75 & 25.00 & 126.91 & 2.611 & 3907 & 49.71 & 24.90 & 126.66 & 2.621 & 3662 \\
\hline \multirow{3}{*}{200} & GB11-21 & 49.94 & 25.19 & 126.75 & 2.570 & 3704 & 49.55 & 25.14 & 125.99 & 2.599 & 3307 \\
\hline & GB11-22 & 49.78 & 25.13 & 127.63 & 2.610 & 3695 & 49.71 & 25.14 & 126.84 & 2.600 & 3492 \\
\hline & GB11-24 & 49.79 & 25.16 & 127.09 & 2.595 & 3700 & 49.61 & 25.16 & 126.48 & 2.602 & 3494 \\
\hline \multirow{3}{*}{300} & GB11-29 & 49.79 & 25.12 & 127.33 & 2.604 & 3925 & 49.74 & 25.07 & 126.36 & 2.594 & 3482 \\
\hline & GB11-30 & 49.97 & 25.00 & 126.57 & 2.581 & 3676 & 49.78 & 24.97 & 125.59 & 2.585 & 3285 \\
\hline & GB11-32 & 49.72 & 25.15 & 127.02 & 2.602 & 3698 & 49.68 & 25.14 & 126.10 & 2.588 & 3696 \\
\hline \multirow{3}{*}{400} & GB11-37 & 49.72 & 25.20 & 126.66 & 2.589 & 3706 & 49.71 & 25.07 & 125.53 & 2.580 & 3299 \\
\hline & GB11-38 & 49.85 & 25.06 & 126.16 & 2.580 & 3685 & 49.73 & 24.97 & 124.91 & 2.575 & 3468 \\
\hline & GB11-39 & 49.62 & 25.02 & 128.47 & 2.655 & 3475 & 49.59 & 25.00 & 126.96 & 2.629 & 3290 \\
\hline \multirow{3}{*}{500} & GB11-46 & 49.63 & 25.23 & 127.89 & 2.621 & 3942 & 49.68 & 25.15 & 124.58 & 2.556 & 3309 \\
\hline & GB11-47 & 49.85 & 25.16 & 128.10 & 2.609 & 3931 & 49.77 & 25.12 & 124.21 & 2.542 & 3306 \\
\hline & GB11-48 & 49.77 & 25.18 & 128.02 & 2.613 & 3703 & 49.72 & 25.16 & 125.00 & 2.559 & 3311 \\
\hline \multirow{3}{*}{600} & GB11-56 & 49.76 & 25.29 & 127.51 & 2.593 & 3719 & 49.93 & 25.35 & 121.85 & 2.455 & 2535 \\
\hline & GB11-57 & 49.76 & 25.18 & 126.96 & 2.593 & 3702 & 49.95 & 25.26 & 120.05 & 2.426 & 2177 \\
\hline & GB11-58 & 49.65 & 24.73 & 127.23 & 2.657 & 3637 & 49.91 & 24.90 & 118.28 & 2.428 & 2490 \\
\hline \multirow{3}{*}{700} & GB11-64 & 49.82 & 25.11 & 127.11 & 2.597 & 3923 & 50.03 & 25.28 & 119.02 & 2.395 & 2039 \\
\hline & GB11-66 & 49.67 & 25.15 & 126.40 & 2.595 & 3929 & 50.03 & 25.34 & 118.43 & 2.378 & 1863 \\
\hline & GB11-67 & 49.76 & 25.18 & 127.11 & 2.596 & 3703 & 49.97 & 25.37 & 119.41 & 2.400 & 2114 \\
\hline \multirow{3}{*}{800} & GB11-74 & 49.85 & 25.10 & 127.28 & 2.599 & 3922 & 50.21 & 25.34 & 118.91 & 2.371 & 1712 \\
\hline & GB11-76 & 49.83 & 25.10 & 127.45 & 2.604 & 3921 & 50.16 & 25.35 & 118.77 & 2.372 & 1760 \\
\hline & GB11-77 & 49.74 & 25.22 & 127.13 & 2.594 & 3941 & 50.08 & 25.40 & 119.19 & 2.383 & 1814 \\
\hline \multirow{3}{*}{900} & GB11-86 & 49.89 & 25.17 & 127.40 & 2.590 & 3932 & 50.26 & 25.49 & 118.82 & 2.351 & 1931 \\
\hline & GB11-87 & 49.70 & 25.13 & 126.06 & 2.586 & 3695 & 50.19 & 25.43 & 117.98 & 2.346 & 1869 \\
\hline & GB11-88 & 49.74 & 25.05 & 126.74 & 2.604 & 3684 & 50.21 & 25.35 & 118.59 & 2.363 & 1864 \\
\hline \multirow{3}{*}{1000} & GB11-94 & 49.77 & 25.15 & 127.12 & 2.598 & 4191 & 50.37 & 25.55 & 117.90 & 2.316 & 1935 \\
\hline & GB11-95 & 49.69 & 25.16 & 127.07 & 2.605 & 3931 & 50.50 & 25.61 & 117.53 & 2.291 & 2001 \\
\hline & GB11-98 & 49.69 & 25.12 & 126.86 & 2.604 & 3306 & 50.31 & 25.53 & 118.54 & 2.335 & 1934 \\
\hline
\end{tabular}

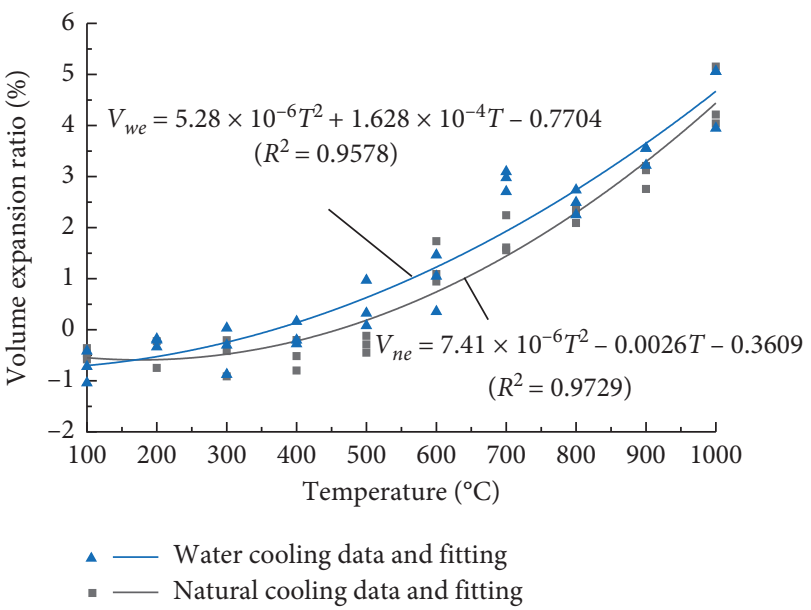

FIGURE 3: Volume expansion rate of high temperature sandstone after two cooling methods.

methods is less affected by temperature. At $500^{\circ} \mathrm{C}$, the density reduction rates of natural cooling and water cooling are $2.37 \%$ and $1.83 \%$. At $600^{\circ} \mathrm{C} \sim 1000^{\circ} \mathrm{C}$, the

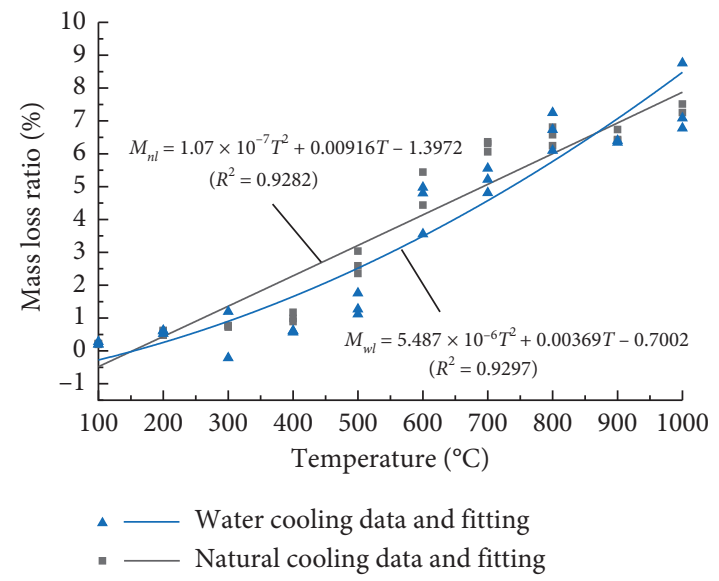

FIGURE 4: Mass loss rate of high temperature sandstone after two cooling methods.

density reduction rate of two cooling methods increases rapidly. The density reduction rates of natural cooling and water cooling are 5.89\% 11.09\% and 5.34\% 11.67\%. As 


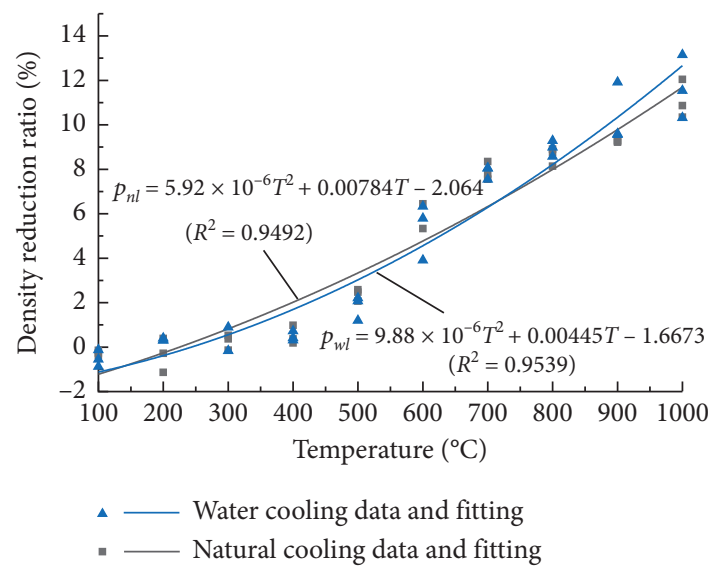

FIGURE 5: Density reduction rate of high temperature sandstone after two cooling methods.

the density is the superposition result of mass and volume, the density reduction rate of two cooling methods is basically the same.

3.3. P-Wave Velocity Variation. Figure 6 shows the variation of P-wave velocity of high temperature sandstone specimens after two cooling methods. Pores and cracks can affect the propagation velocity of ultrasonic wave in the medium. Analyzing the variation of $\mathrm{P}$-wave velocity can help to understand the development of pores and cracks in high temperature rock indirectly and then understand the variation of mechanical properties.

As seen from Figure 6, the P-wave velocities of sandstone specimens after two cooling methods decrease with the temperature. At $100^{\circ} \mathrm{C} \sim 500^{\circ} \mathrm{C}$, the $\mathrm{P}$-wave velocities of the two cooling methods have little difference and the P-wave velocity of water cooling is slightly larger than that of natural cooling. That is because high temperature sandstone cooled in water can make water enter into the specimen, which improves the density of sandstone specimen.

At $600^{\circ} \mathrm{C}$, the P-wave velocity of specimens after two cooling methods decreases significantly, and the drop was about $1000 \mathrm{~m} / \mathrm{s}$. There are two reasons for this large drop. On the one hand, the original moisture inside the specimen is evaporated due to high temperature, then the compactness of the specimen is reduced, and the porosity is increased. On the other hand, due to different thermal expansion coefficients of mineral particles in the specimen, the uneven expansion occurs. The expansion leads to the extension and initiation of pores and cracks inside and on the surface of the specimen. The pores and cracks will hinder the P-wave propagation in the specimen. Therefore, the P-wave velocities after two cooling methods decrease significantly.

The P-wave velocity of natural cooling specimens tends to be stable at $700^{\circ} \mathrm{C} \sim 1000^{\circ} \mathrm{C}$, indicating that the pores and cracks in the specimen have been fully developed. The wave velocity of water cooling decreases to $1857 \mathrm{~m} / \mathrm{s}$ at $800^{\circ} \mathrm{C}$ and further decreased to $1593 \mathrm{~m} / \mathrm{s}$ and $1475 \mathrm{~m} / \mathrm{s}$ at $900^{\circ} \mathrm{C}$ and $1000^{\circ} \mathrm{C}$. The P-wave velocity reduction rate of water cooling is slightly bigger than that of natural cooling. When high

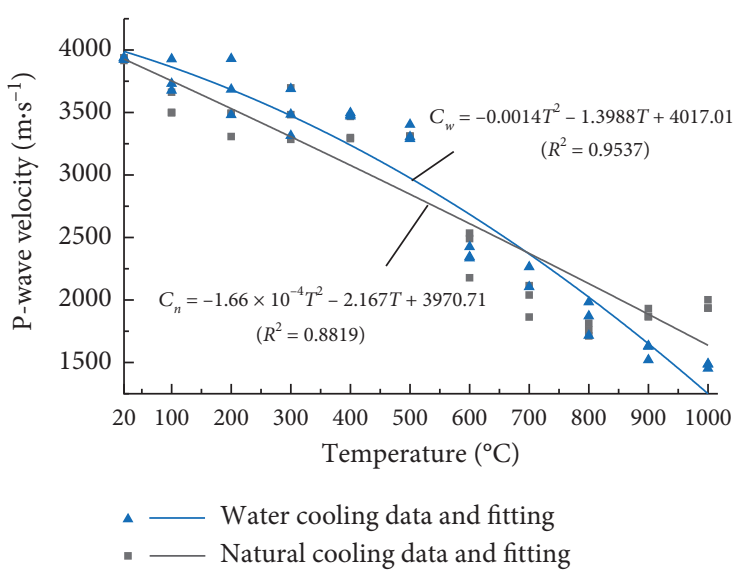

FIgURE 6: P-wave velocity of high temperature sandstone after two cooling methods.

temperature sandstone specimen is cooled in water, there is a large temperature difference between the inner and outer layers of sandstone specimen. At this time, the outer layer of the specimen will shrink, while the inner part of the specimen is still in a state of thermal expansion. Therefore, tensile stress is generated in the outer layer of the specimen, and the tensile stress generated by this temperature difference will gradually emerge from outside to inside with the cooling effect. Developed pores and cracks in the inner and on the surface of the specimen result in further attenuation of $\mathrm{P}$-wave energy. Therefore, the decrease rate of $\mathrm{P}$-wave velocity of water cooling is greater than that of natural cooling.

3.4. Dynamic Compressive Stress-Strain Curve. Based on impact compression tests, Figure 7 presents the dynamic compressive stress-strain curves of high temperature sandstone after two cooling methods.

As seen from Figure 7, the dynamic stress-strain curves of high temperature sandstone specimens after two cooling methods have experienced four stages. In the first stage, the stress slowly increases with the strain, called the compaction stage. The slope of stress-strain curve is small, and it is in a state of slow upward. In this stage, the micropores and microcracks in the specimen are compacted and closed under the impact load, and this stage is very short. In the second stage, the slope of stress-strain curve increases and remains constant. The stress-strain curve in this stage is approximately a straight line, and the rock is in an elastic deformation stage. In the third stage, the slope of stressstrain curve begins to decrease, and the curve is in a convex shape, called the plastic strengthening stage. In the fourth stage, the slope of stress-strain curve is negative, called the failure stage. Under the continuous action of impact load, the rock begins to break and the bearing capacity of rock begins to decline.

It can be seen that the dynamic stress-strain curves of two cooling methods are basically consistent. The stressstrain curve of water cooling is lower and wider than that of natural cooling. The reason for this difference is that the compaction stage of water cooling is longer than that of 


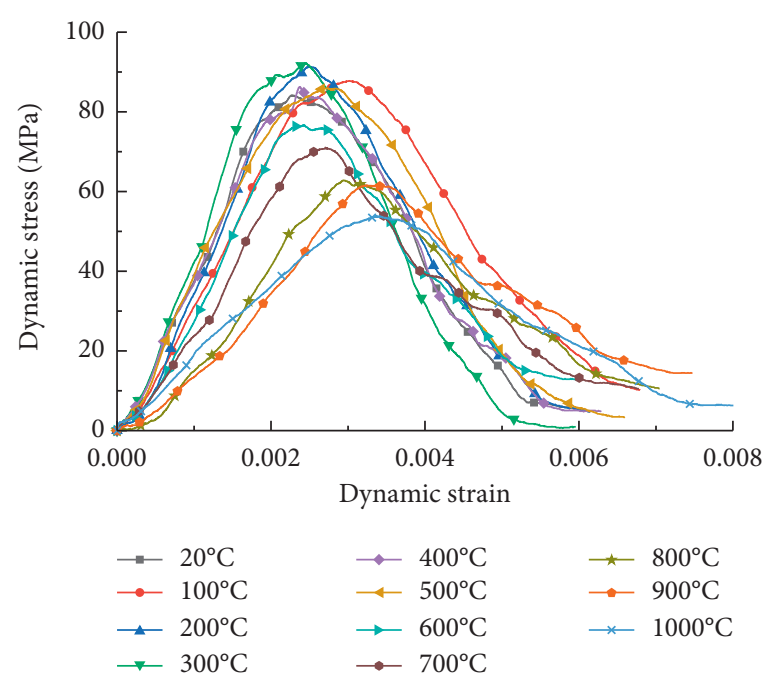

(a)

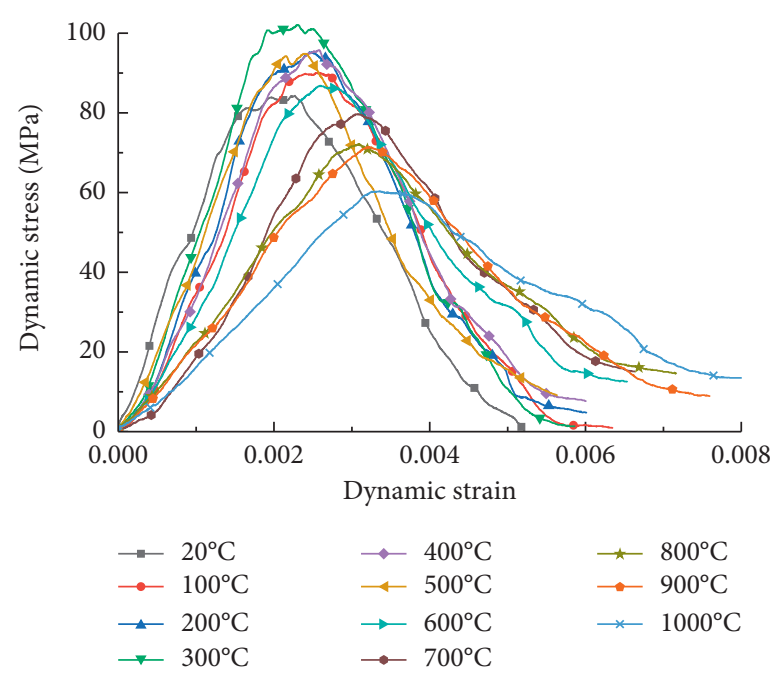

(b)

FIgURe 7: Dynamic stress-strain curves of high temperature sandstone after two cooling methods: (a) water cooling; (b) natural cooling.

natural cooling. Rapid cooling of high temperature sandstone specimen in water intensifies the development of micropores and microcracks, and the compression displacement of impact force increases with more pores in the specimen. Therefore, the compaction stage of water cooling is longer than that of natural cooling. In the elastic stage, the slope of stress-strain curves of water cooling is smaller than that of natural cooling, namely, the dynamic elastic modulus of water cooling is smaller than that of natural cooling. In the third stage, the dynamic peak stress of water cooling is lower than that of natural cooling, while the corresponding dynamic strain of water cooling is slightly larger than that of natural cooling.

3.5. Dynamic Compressive Strength. Dynamic compressive strength $\left(\sigma_{d}\right)$ of high temperature sandstone specimens ranging from room temperature $\left(20^{\circ} \mathrm{C}\right)$ to $1000^{\circ} \mathrm{C}$ after two cooling methods is shown in Figure 8.

As seen from Figure 8, the dynamic compressive strength of water cooling sandstone specimens is significantly lower than that of natural cooling. The dynamic compressive strength of two cooling methods increases first and then decreases with the temperature and reaches the maximum at $300^{\circ} \mathrm{C}$. When heating temperature exceeds $300^{\circ} \mathrm{C}$, the dynamic compressive strength of two cooling methods decreases in a quadratic function with the temperature, as shown in the following equation:

$$
\left.\begin{array}{l}
\sigma_{w d}=-9.06 \times 10^{-6} T^{2}-0.044 T+106.58\left(R^{2}=0.9801\right), \\
\sigma_{n d}=-1.75 \times 10^{-5} T^{2}-0.036 T+114.29\left(R^{2}=0.9802\right)
\end{array}\right\},
$$

where $\sigma_{w d}$ and $\sigma_{n d}$ are the dynamic compressive strength of water cooling and natural cooling and $T$ is the heating temperature.

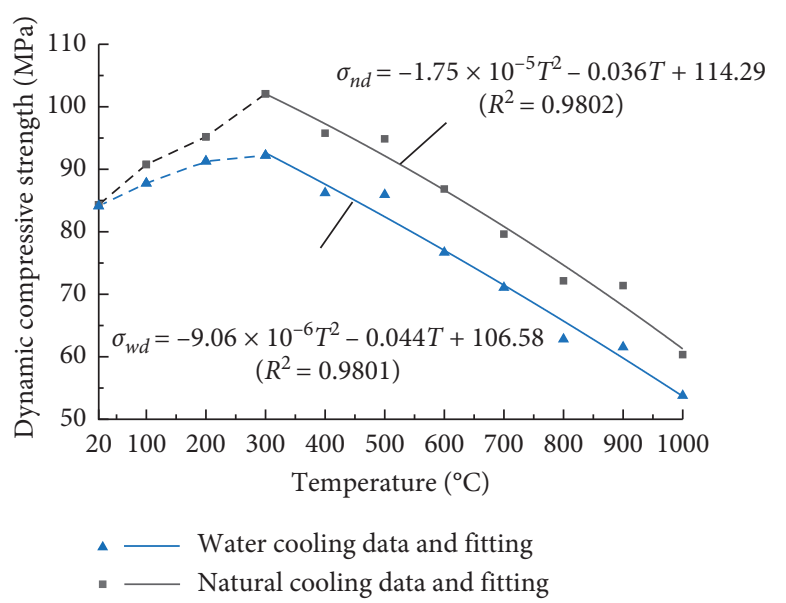

FIGURE 8: Dynamic compressive strength of high temperature sandstone after two cooling methods.

When the temperature is $100^{\circ} \mathrm{C} \sim 300^{\circ} \mathrm{C}$, the dynamic compressive strength of two cooling methods increases with the temperature. This is because when the temperature is low, the expansion of heated mineral particles inside the sandstone specimen can fill the original micropores and microcracks, which improve the compactness and dynamic compressive strength of sandstone specimen. Moreover, the evaporation of water will increase the friction force between mineral particles, which also increase the dynamic compressive strength. According to above analysis, water cooling will cause additional damage to high temperature sandstone. During water cooling, the friction between mineral particles is weakened as water enters into the specimen. Therefore, the dynamic compressive strength of water cooling is lower than that of natural cooling.

With the increase in heating temperature, the difference of dynamic compressive strength between water cooling and natural cooling is gradually larger and the difference is the 
largest at $800^{\circ} \mathrm{C}$ and $900^{\circ} \mathrm{C}$. The dynamic compressive strength of water cooling is $12.92 \%$ and $13.77 \%$ lower than that of natural cooling, indicating that water cooling causes an obvious degradation for high temperature sandstone. At $1000^{\circ} \mathrm{C}$, the difference between water cooling and natural cooling decreases, indicating that after the high temperature of $1000^{\circ} \mathrm{C}$, the thermal damage caused by high temperature gradually becomes the main factor of degradation.

3.6. Dynamic Elastic Modulus. As seen from Figure 9, the dynamic elastic modulus of water cooling sandstone specimens is smaller than that of natural cooling. The dynamic elastic modulus of two cooling methods first increases and then decreases with the temperature. The maximum dynamic elastic modulus is at $300^{\circ} \mathrm{C}$, and the dynamic elastic modulus of two cooling methods is basically consistent at $1000^{\circ} \mathrm{C}$. There is a quadratic function between the dynamic elastic modulus of sandstone and temperature, as shown in the following equation:

$$
\left.\begin{array}{l}
E_{w d}=-4.55 \times 10^{-5} T^{2}+0.018 T+43.40\left(R^{2}=0.9710\right), \\
E_{n d}=-7.14 \times 10^{-5} T^{2}+0.046 T+42.90\left(R^{2}=0.9481\right)
\end{array}\right\},
$$

where $E_{w d}$ and $E_{n d}$ are the dynamic elastic modulus of water cooling and natural cooling and $T$ is the heating temperature.

When the temperature is $100^{\circ} \mathrm{C} \sim 300^{\circ} \mathrm{C}$, the dynamic elastic modulus of two cooling methods increases with the temperature. While when the temperature exceeds $300^{\circ} \mathrm{C}$, the dynamic elastic modulus of two cooling methods decreases. With the increase in temperature, the difference of the dynamic elastic modulus between two cooling methods first increases and then decreases. At $500^{\circ} \mathrm{C}$, the difference is the largest, and the dynamic elastic modulus value of natural cooling is $28.13 \%$ higher than that of water cooling, indicating that water cooling significantly deteriorates the dynamic mechanical properties of high temperature sandstone. At $1000^{\circ} \mathrm{C}$, the difference between two cooling methods decreases. The dynamic elastic modulus of natural cooling is 20.09 GPa and the dynamic elastic modulus of water cooling is $18.22 \mathrm{GPa}$, which are basically consistent. Hence, high temperature gradually becomes the main factor affecting the dynamic mechanical properties of sandstone, but water cooling still has a certain effect.

3.7. Dynamic Strain and Strain Rate. Dynamic strain of sandstone specimens after water cooling and natural cooling is shown in Figure 10.

As seen from Figure 10, the dynamic strain of water cooling sandstone specimens is greater than that of natural cooling. The dynamic strain of two cooling methods increases in a quadratic function with the temperature, as shown in the following equation:

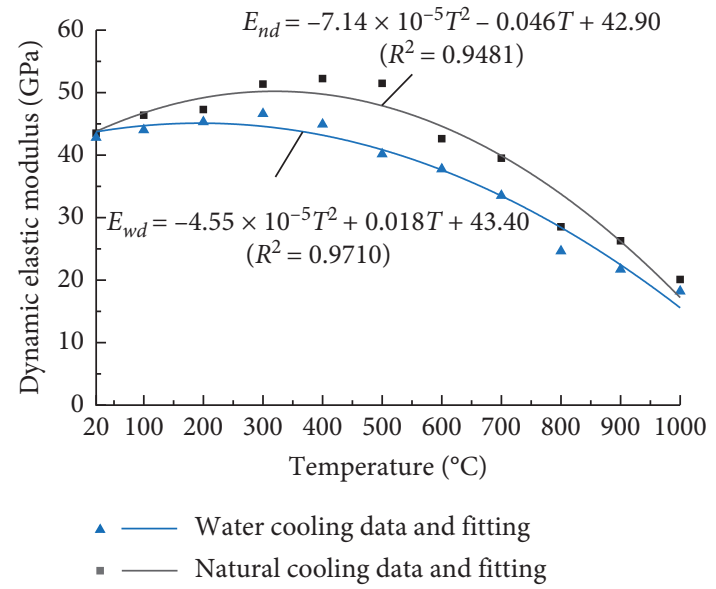

Figure 9: Dynamic elastic modulus of high temperature sandstone after two cooling methods.

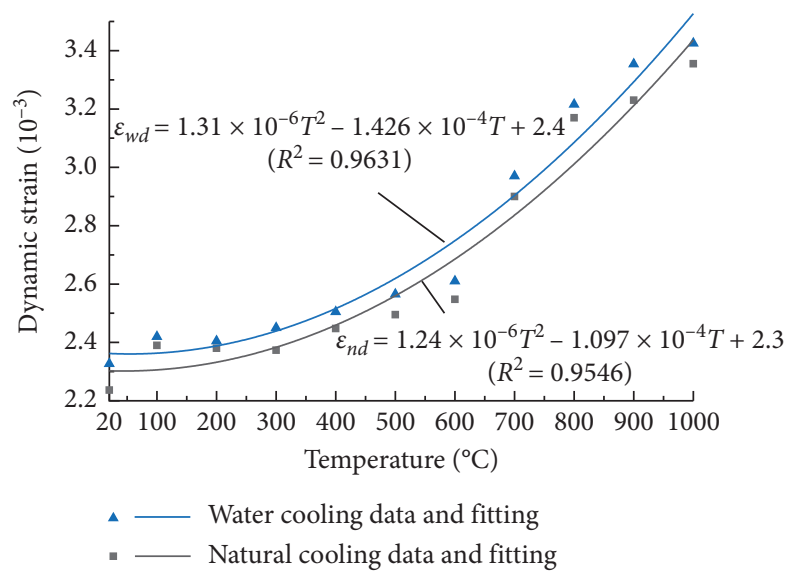

FIgURe 10: Dynamic strain of high temperature sandstone after two cooling methods.

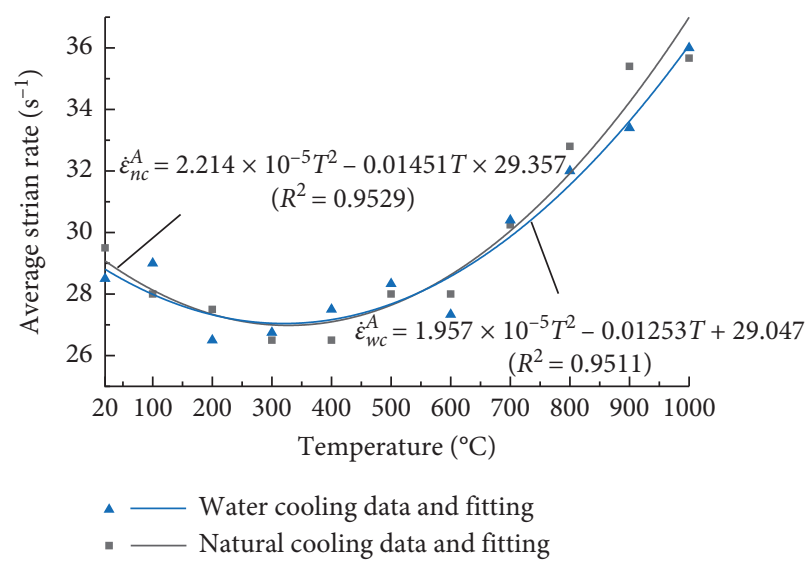

FIGURE 11: Average strain rate of high temperature sandstone after two cooling methods. 


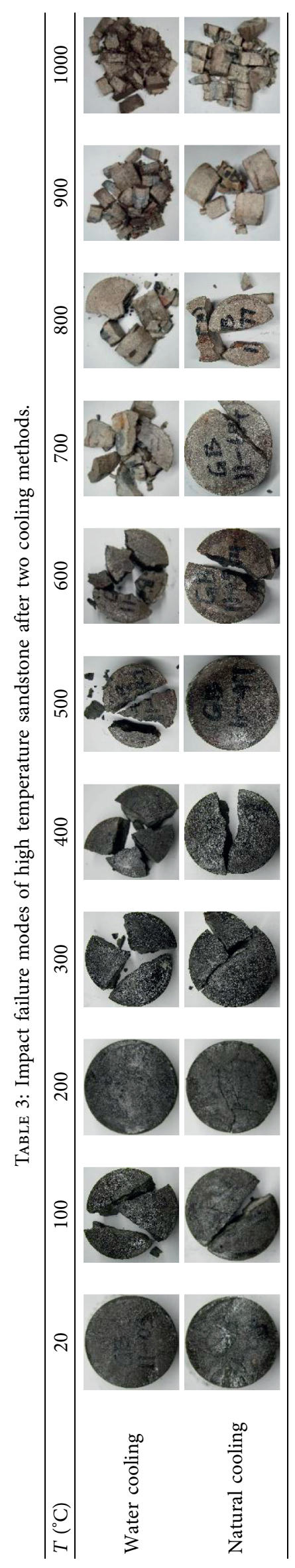




$$
\left.\begin{array}{l}
\varepsilon_{w d}=1.31 \times 10^{-6} T^{2}-1.426 \times 10^{-4} T+2.4\left(R^{2}=0.9631\right), \\
\varepsilon_{n d}=1.24 \times 10^{-6} T^{2}-1.097 \times 10^{-4} T+2.3\left(R^{2}=0.9546\right),
\end{array}\right\},
$$

where $\varepsilon_{w d}$ and $\varepsilon_{n d}$ are the dynamic strain of water cooling and natural cooling and $T$ is the heating temperature.

When the temperature is $100^{\circ} \mathrm{C} \sim 300^{\circ} \mathrm{C}$, the dynamic strain of two cooling methods is not significantly affected by temperature. The dynamic strain of natural cooling and water cooling is $2.24 \times 10^{-3} \sim 2.37 \times 10^{-3}$ and $2.33 \times 10^{-3} \sim$ $2.45 \times 10^{-3}$. From $400^{\circ} \mathrm{C}$, the dynamic strain of two cooling methods begins to increase gradually, and the increase was the largest at $700^{\circ} \mathrm{C}$.

Average strain rate of high temperature sandstone after two cooling methods has little difference. With the increase in temperature, the strain rate first decreases and then increases, and there is a quadratic function between strain rate and temperature, as shown in Figure 11.

3.8. Impact Failure Modes of Specimens. As seen from the impact failure modes listed in Table 3, the impact failure degree of sandstone specimens increases with the temperature and the impact failure degree of water cooling specimens is significantly greater than that of natural cooling. Corresponding to the variation of dynamic compressive strength and dynamic peak stress, the impact failure degree of two cooling methods first decreases and then increases with the increase in the heating temperature, which is basically consistent with the result of Ping et al. [31].

When the temperature is $400^{\circ} \mathrm{C} \sim 1000^{\circ} \mathrm{C}$, the failure degree of water cooling sandstone specimens is obviously greater than that of natural cooling and the degree of fragmentation increases with the increase in heating temperature. When the temperature is $900^{\circ} \mathrm{C}$ and $1000^{\circ} \mathrm{C}$, the number of granular fragments of water cooling increases obviously and the color of fragments of water cooling is darker than that of natural cooling, which is black-brown. It shows that under the combined action of high temperature and water cooling, the iron oxide content in sandstone specimens increases significantly.

\section{Conclusions}

Natural cooling and water cooling are used to cool high temperature sandstone specimens with 11 temperature gradients ranging from room temperature $\left(20^{\circ} \mathrm{C}\right)$ to $1000^{\circ} \mathrm{C}$. Then, SHPB impact compression tests are carried out for sandstone specimens after heating and cooling under the same loading conditions. The conclusions are drawn as follows:

(1) The volume expansion rate, mass loss rate, density reduction rate, and $\mathrm{P}$-wave velocity reduction rate of sandstone specimens after two cooling methods are positively correlated with temperature in a quadratic function. The deteriorate rate of physical parameters of water cooling sandstone specimens is slightly larger than that of natural cooling. The $\mathrm{P}$-wave velocity of sandstone decreases with the temperature.
When the temperature is $600^{\circ} \mathrm{C}$, the $\mathrm{P}$-wave velocity of specimens after two cooling methods decreases most. When the temperature is $700^{\circ} \mathrm{C} \sim 1000^{\circ} \mathrm{C}$, the $\mathrm{P}$-wave velocity of natural cooling sandstone tends to be stable and no obvious decrease occurs while the P-wave velocity of water cooling continues to decrease.

(2) The dynamic compressive strength of water cooling sandstone specimens is significantly lower than that of natural cooling. The dynamic compressive strength of water cooling and natural cooling first increases and then decreases with the temperature. At $300^{\circ} \mathrm{C}$, the dynamic compressive strength of two cooling methods is the largest, and then dynamic compressive strength decreases in a quadratic function with the temperature. At $800^{\circ} \mathrm{C}$ and $900^{\circ} \mathrm{C}$, the difference of dynamic compressive strength between water cooling and natural cooling is the largest, while the difference of dynamic compressive strength decreases at $1000^{\circ} \mathrm{C}$. The dynamic elastic modulus of water cooling sandstone specimens is less than that of natural cooling. The dynamic elastic modulus of two cooling methods first increases and then decreases with the temperature. The maximum is at $300^{\circ} \mathrm{C}$. At $1000^{\circ} \mathrm{C}$, the difference of the dynamic elastic modulus between two cooling methods decreases.

(3) The dynamic strain of water cooling sandstone specimens is greater than that of natural cooling. The dynamic strain of two cooling methods increases with the temperature. When the temperature is between $100^{\circ} \mathrm{C}$ and $300^{\circ} \mathrm{C}$, the dynamic strain of two cooling methods is not obviously affected by the temperature. From $400^{\circ} \mathrm{C}$, the dynamic strain value of two cooling methods begins to increase gradually, and the biggest increase is at $700^{\circ} \mathrm{C}$. The average strain rate of two cooling methods is basically consistent, and the average strain rate is positively correlated with temperature in a quadratic function.

(4) The impact failure degree increases with heating temperature, and the impact failure degree of water cooling sandstone specimens is significantly greater than that of natural cooling. The impact failure degree of two cooling methods first decreases and then increases with the temperature, which corresponds to the variation of dynamic compressive strength. At $900^{\circ} \mathrm{C}$ and $1000^{\circ} \mathrm{C}$, the number of granular fragments of water cooling increases obviously, and the color of fragments of water cooling is darker than that of natural cooling, which is black-brown, indicating that the iron oxide content in sandstone specimens increases significantly under the combined action of high temperature and water cooling.

\section{Data Availability}

The datasets generated and analyzed in the current study are obtained from the corresponding author upon reasonable request. 


\section{Conflicts of Interest}

The authors declare that they have no conflicts of interest regarding the publication of this paper.

\section{Acknowledgments}

This research received financial supports from the National Natural Science Foundation of China (nos. 52074005, 52074006, and 51674008), Anhui Provincial Natural Science Foundation (no. 1808085ME134), and Anhui Postdoctoral Science Foundation (no. 2015B058). The authors would like to thank the State Key Laboratory of Mining Response and Disaster Prevention and Control in Deep Coal Mine, Engineering Research Center of Underground Mine Construction, Ministry of Education, and Anhui University of Science and Technology, for providing the experiment conditions.

\section{References}

[1] J. Yu, W. Yao, K. Duan, X. Liu, and Y. Zhu, "Experimental study and discrete element method modeling of compression and permeability behaviors of weakly anisotropic sandstones," International Journal of Rock Mechanics and Mining Sciences, vol. 134, pp. 1-14, Article ID 104437, 2020.

[2] J. Yu, C. H. Ren, Y. Y. Cai, and W. Yao, "Analytical approach for evaluating the dynamic self-bearing capacity of tunnels," International Journal of Geomechanics, vol. 21, no. 8, pp. 1-15, Article ID 04021133, 2021.

[3] N. N. Sirdesai, T. N. Singh, P. G. Ranjith, and S. Rajesh, "Effect of varied durations of thermal treatment on the tensile strength of red sandstone," Rock Mechanics and Rock Engineering, vol. 2017, no. 50, 213 pages, 2017.

[4] S. Q. Yang, W. L. Tian, and J. P. Dong, "Experimental study on failure mechanical properties of granite with two grain sizes after thermal treatment," Chinese Journal of Geotechnical Engineering, vol. 43, no. 2, pp. 281-289, 2021.

[5] L. S. Gao, Y. Xu, and B. B. Wu, "Dynamic compression strength of thermal damaged Fangshan marble on dry and saturated conditions," Chinese Journal of Rock Mechanics and Engineering, vol. 37, no. supp2, pp. 3827-3833, 2018.

[6] Q. Ping, C. Zhang, H. Su, and H. Zhang, "Experimental study on dynamic mechanical properties and energy evolution characteristics of limestone specimens subjected to high temperature," Advances in Civil Engineering, vol. 2020, Article ID 8875568, 12 pages, 2020.

[7] Q. Ping, M. Wu, P. Yuan, H. Su, and H. Zhang, "Dynamic splitting experimental study on sandstone at actual high temperatures under different loading rates," Shock and Vibration, vol. 2020, Article ID 8867102, 12 pages, 2020.

[8] L. P. Zhi, J. Y. Xu, Z. Q. Liu, and S. Liu, "Research on impacting failure behavior and fluctuation characteristics of granite exposed to high temperature," Chinese Journal of Rock Mechanics and Engineering, vol. 32, no. 1, pp. 135-142, 2013.

[9] L. Y. Zhang and X. B. Mao, "Experimental study of the mechanical effects of loading rates on limestone at high temperature," Rock and Soil Mechanics, vol. 31, no. 11, pp. 3511-3515, 2010.

[10] Q. Ping, H. P. Su, D. D. Ma, H. Zhang, and C. Zhang, "Experimental study on physical and dynamic mechanical properties of limestone after different high temperature treatment," Rock and Soil Mechanics, vol. 42, no. 4, pp. 1-12, 2021.

[11] Q. Ping, M. J. Wu, P. Yuan et al., "Experimental study on dynamic mechanical properties of high temperature sandstone under impact loads," Chinese Journal of Rock Mechanics and Engineering, vol. 38, no. 4, pp. 782-792, 2019.

[12] S. Liu, J. Y. Xu, L. P. Zhi, and T. Chen, "Experimental research on mechanical behaviors of marble after high temperatures subjected to impact loading," Chinese Journal of Rock Mechanics and Engineering, vol. 32, no. 2, pp. 273-280, 2013.

[13] Y. B. Li, Y. Zhai, and C. S. Wang, "Mechanical properties of Beishan granite under complex dynamic loads after thermal treatment," Engineering Geology, vol. 267, pp. 1-10, Article ID 105481, 2020.

[14] B. P. Xi and Y. S. Zhao, "Experimental research on mechanical properties of water-cooled granite under high temperatures within $600^{\circ} \mathrm{C}$," Chinese Journal of Rock Mechanics and Engineering, vol. 29, no. 5, pp. 892-898, 2010.

[15] A. B. Jin, S. L. Wang, Y. D. Wei, H. Sun, and L. Wei, "Effect of different cooling conditions on physical and mechanical properties of high-temperature sandstone," Rock and Soil Mechanics, vol. 44, no. 11, pp. 3531-3539, 2020.

[16] Z. N. Zhu, H. Tian, N. N. Dong, and B. Dou, "Experimental study of physico-mechanical properties of heat-treated granite by water cooling," Rock and Soil Mechanics, vol. 39, no. s2, pp. 169-176, 2018.

[17] Z. P. Huang, Y. Zhang, Y. K. Sun, and C. Liu, "Mechanical and acoustic characteristics of high temperature limestone with water cooling treatment," Journal of Central South University, vol. 47, no. 12, pp. 4181-4189, 2016.

[18] Z. P. Huang, Y. Zhang, and W. D. Wu, "Analysis of mechanical and wave properties of heat-treated marble by water cooling," Rock and Soil Mechanics, vol. 37, no. 2, pp. 367-375, 2016.

[19] G. S. Han, H. W. Jing, and H. J. Su, "Experimental research on mechanical behaviors of water-cooled sandstone after high temperature treatment," Journal of China University of Mining and Technology, vol. 49, no. 1, pp. 69-75, 2020.

[20] Y. Zhai, X. Q. Ai, Z. C. Deng, and W. He, "Influences of cooling mode and high temperature on concrete compressive strength," Journal of Hunan University, vol. 41, no. 11, pp. 74-80, 2014.

[21] P. Wang, Y. L. Chen, and X. L. Zhou, "Impact of rapid cooling in water on residual mechanical properties of granite under high temperature," Journal of Water Resources \& Water Engineering, vol. 24, no. 3, pp. 54-63, 2013.

[22] X. C. Shi, L. Y. Gao, and J. Wu, "Effects of cyclic heating and water cooling on the physical characteristics of granite," Energies, vol. 13, Article ID 2136, 2020.

[23] Q. Li, T. B. Yin, X. B. Li, and S. Zhang, "Effects of rapid cooling treatment on heated sandstone: a comparison between water and liquid nitrogen cooling," Bulletin of Engineering Geology and the Environment, vol. 2020, no. 79, 327 pages, 2020.

[24] G. S. Han, H. W. Jing, and H. J. Su, "Effects of thermal shock due to rapid cooling on the mechanical properties of sandstone," Environmental Earth Sciences, vol. 78, Article ID 146, 2019.

[25] T. D. Rathnaweera, P. G. Ranjith, X. Gu et al., "Experimental investigation of thermomechanical behaviour of clay-rich sandstone at extreme temperatures followed by cooling treatments," International Journal of Rock Mechanics and Mining Sciences, vol. 107, no. 107, pp. 208-223, 2018.

[26] T. B. Yin, Q. Li, and X. B. Li, "Experimental investigation on mode I fracture characteristics of granite after cyclic heating 
and cooling treatments," Engineering Fracture Mechanics, vol. 222, Article ID 106740, 2019.

[27] Z. Zhu, H. Tian, G. Mei, G. Jiang, and B. Dou, "Experimental investigation on physical and mechanical properties of thermal cycling granite by water cooling," Acta Geotechnica, vol. 15, no. 7, pp. 1881-1893, 2020.

[28] Y. L. Zhu, J. Yu, and H. D. Gao, "Effect of water cooling on microscopic damage and dynamic properties of high-temperature granite," Explosion and Shock Waves, vol. 39, no. 8, pp. 083104-1-083104-11, 2019.

[29] Y. Zhai, Y. Li, Y. Li, W Jiang, and X Liu, "Research on the impact loading and energy dissipation of concrete after elevated temperature under different heating gradients and cooling methods," Materials, vol. 11, no. 9, pp. 1-20, Article ID 1651, 2018.

[30] International Society for Rock Mechanics (Isrm), "Suggested methods for determining tensile strength of rock materials," International Journal of Rock Mechanics and Mining Science \& Geomechanics Abstracts, vol. 15, no. 1, pp. 99-103, 1978.

[31] Q. Ping, M. J. Wu, H. Zhang et al., "Experimental study on dynamic mechanical characteristics of sandstone under actual high temperature conditions," Chinese Journal of Underground Space and Engineering, vol. 15, no. 3, pp. 691-698, 2019. 